\section{$\underset{\substack{\text { hommes } \\ \text { \& migrations }}}{ }$}

\section{Hommes \& migrations}

Revue française de référence sur les dynamiques

migratoires

\section{$1288 \mid 2010$}

Langues et migrations

\title{
Éloge de Babel
}

\section{Philippe Lazar}

\section{OpenEdition \\ Journals}

Édition électronique

URL : http://journals.openedition.org/hommesmigrations/864

DOI : 10.4000/hommesmigrations.864

ISSN : 2262-3353

\section{Éditeur}

Musée national de l'histoire de l'immigration

Édition imprimée

Date de publication : 1 novembre 2010

Pagination : 74-79

ISSN : 1142-852X

Référence électronique

Philippe Lazar, « Éloge de Babel », Hommes \& migrations [En ligne], 1288 | 2010, mis en ligne le 29 mai 2013, consulté le 03 mai 2019. URL : http://journals.openedition.org/hommesmigrations/864 ; DOI :

10.4000/hommesmigrations.864 


\section{Éloge de Babel}

Par Philippe Lazar, directeur de la revue

Diasporiques/Cultures en mouvement

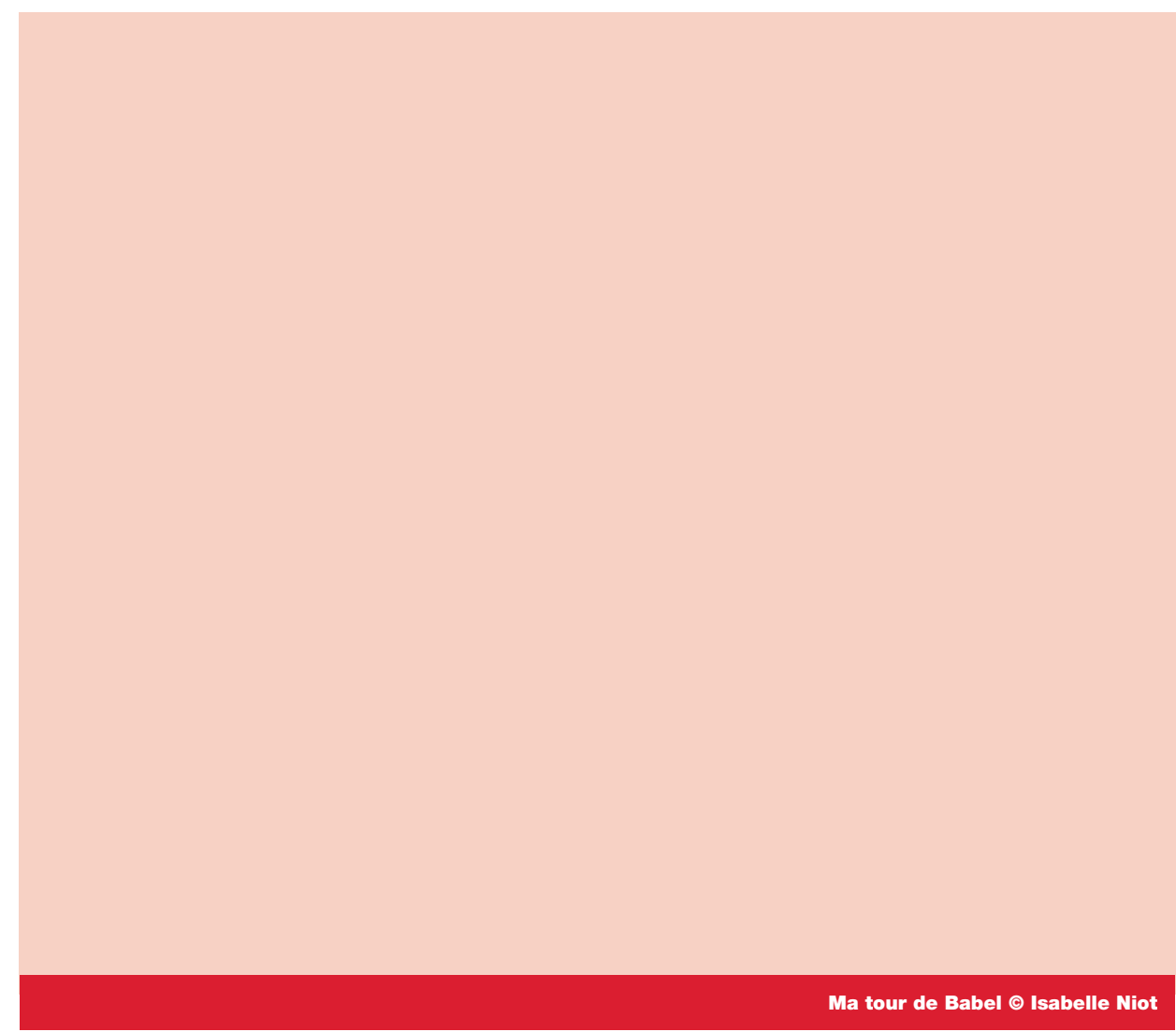

Le mythe de Babel incarne le malentendu persistant de la communication humaine. Le cloisonnement des idiomes interroge la capacité des hommes de se comprendre à l'échelle planétaire. À l'heure où les identités trouvent refuge derrière les frontières rassurantes des communautés, où se diffuse le modèle dominant d'une culture mondialisée, il convient de dépasser le clivage entre les langues majoritaires et celles qui sont minorées. Loin de pointer les limites entre les hommes, Babel indique le chemin de l'autre : le partage de sa langue. 


\section{Langues et cultures : des biens publics}

Langues et cultures ne peuvent demeurer vivantes que si elles ont un nombre conséquent, s'agissant des premières, de locuteurs et, pour les secondes, de passeurs. Ces deux qualifications ne confèrent pour autant à leurs titulaires aucun droit de propriété sur les objets culturels qu'ils contribuent spécifiquement à entretenir et à diffuser et qui devraient être formellement considérés comme des biens publics de l'humanité. Au-delà de la construction, légitime, de leur identité personnelle, ces acteurs sont porteurs d'une responsabilité collective au service de la préservation de la diversité linguistique et culturelle, cette entité aussi précieuse - bien qu'on s'en préoccupe habituellement avec beaucoup moins d'ardeur que de la biodiversité... Laffirmation de principe - le postulat pourrait-on dire - de l'universalité des biens culturels et de leur caractère fondamentalement non privatif est pourtant loin de faire l'unanimité. On a même de bonnes raisons de craindre aujourd'hui que ce ne soit la tendance inverse qui l'emporte. En contrepoint du processus, sans doute irréversible, de mondialisation de l'économie et d'inclusion forcée des faits de culture dans ce maelström, grande est en effet la tentation des replis communautaires et du développement d'un multicommunautarisme perçu comme protecteur des "identités". Comme si une identité pouvait se réduire à une appartenance monoculturelle et comme si le rouleau compresseur de l'uniformisation engendrée par la dominance mondiale d'un capitalisme devenu essentiellement spéculatif ne se jouait pas de cet éclatement en micro-cultures! Diviser pour régner est une doctrine qui vaut aussi en la matière...

\section{Espace des individus et espaces des cultures}

Pour tenter d'échapper un tant soit peu au risque d'enfermement évoqué, il faut prendre conscience de la distinction formelle à établir entre individus et faits de culture. Les premiers - quelque six à sept milliards aujourd'hui - constituent un ensemble (un "espace") des plus concrets ; chacun d'eux, unique dans l'histoire de l'humanité, est strictement non reproductible ; même les "vrais" jumeaux présentent de notables différences au-delà de leur très étroite parenté génétique. Les faits de culture sont, eux, de nature tout à fait différente : ils sont d'ordre abstrait (même si leurs supports et leurs modalités de diffusion sont parfaitement matériels); ils sont la résultante de l'extrême enchevêtrement des réseaux relationnels institués entre les 
hommes au fil des millénaires ; ils sont dépositaires de l'histoire et de la multiplicité des mémoires collectives.

Chaque être humain, s'il est d'abord un corps-esprit, parfaitement individué, ne devient réellement une personne que dans sa relation aux autres. "On se connaît, on se construit par le contact, l'échange, le commerce avec l'autre", nous dit de façon définitive Jean-Pierre Vernant dans La Traversée des frontières ${ }^{(1)}$. Nous vivons - nous respirons, nous nous nourrissons, nous nous développons, nous pensons - dans ce qu'on peut appeler l'espace des corps ; mais nous n'accédons réellement à notre humanité dans sa complétude que dans l'espace complémentaire de nos relations aux autres, à tous les autres, un espace que je me suis personnellement autorisé à appeler "espace des âmes ${ }^{(2)}$ ", en dehors de toute acception transcendantale.

C'est dans l'espace des âmes - cet espace privilégié des échanges - que se structurent les liens constitutifs des communautés humaines, quelle que soit leur nature : familiale, géographique, historique, nationale, etc., et, bien entendu, linguistique. Ces communautés sont le fruit direct des proximités de tous ordres, des "voisinages" qui façonnent les relations entre nos semblables. Ces communautés porteuses de faits de

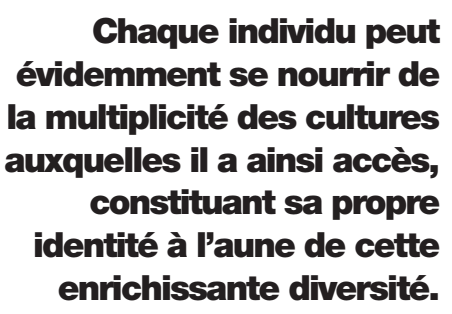
culture sont ainsi à la fois identifiables et à bords "flous" : elles s'insèrent dans le vaste ensemble de la communauté humaine sans nulle obligation d'enfermement dans des frontières à visée protectionniste. "Luniversel, c'est le local moins les murs", affirme on ne peut plus justement l'écrivain portugais Miguel Torga $^{(3)}$. Rien de plus naturel que de vouloir protéger une part de soi-même en n'oubliant pas ses racines, même si les aléas de l'existence ou des choix personnels en ont réduit l'influence. Rien n'oblige à rejeter voire à oublier sa langue maternelle même si elle n'est plus sa langue véhiculaire. Mais l'accès à l'universalité passe nécessairement par une double démarche : se reconnaître, si peu que ce soit, par souci de réciprocité, autre pour l'autre; accepter l'autre dans son altérité comme un élément essentiel d'accomplissement individuel et collectif.

En d'autres termes encore, il y a parfaite complémentarité des rôles entre l'espace des individus et celui des âmes, cet espace où se déploient les cultures et où elles peuvent interagir, sauf si elles décident de se replier de façon exclusive sur ellesmêmes. Et chaque individu peut évidemment se nourrir de la multiplicité des cultures auxquelles il a ainsi accès, constituant sa propre identité à l'aune de cette enrichissante diversité. 


\section{Babel, un trésor de l'humanité}

Dans cette optique, la pluralité des langues en usage à Babel ne saurait se réduire à son interprétation religieuse de cloisonnement punitif de l'humanité en entités incapables de communiquer les unes avec les autres. Au premier degré, on peut certes déplorer l'existence de cette barrière linguistique généralisée et les fermetures réciproques qui en résultent. Mais on ne saurait en rester là. L'unification linguistique est d'abord, qu'on le veuille ou non, outil irremplaçable de pouvoir, qu'il s'agisse d'asseoir un pouvoir étatique ou de consolider une emprise économique et culturelle. La volonté politique, longtemps dominante dans notre pays, d'éradiquer les langues régionales illustre le premier de ces aspects, le rôle insidieux du pidgin américain dans l'extension mondiale du capitalisme international témoigne du second.

On peut dès lors donner du mythe de Babel une tout autre lecture. La multiplicité des idiomes ne résulte bien sûr nullement de la volonté divine d'interdire aux hommes de se prétendre à l'égal des dieux, elle est simplement le reflet de la richesse évolutive de l'humanité. Le fait que, majoritairement, mes "semblables" ne me ressemblent ni dans leur apparence physique ni dans la nature des sons articulés qu'ils émettent me met directement en présence de ce fascinant patrimoine. La conscience de la distance qui me sépare, de ce fait, d'eux peut bien sûr induire des réactions de rejet.

Mais cette "étrangeté" peut aussi, tout au contraire, éveiller ma curiosité, me donner le désir de sortir du chemin tracé par mes origines, ma langue maternelle, la ou les cultures dont je suis imprégné... Ce n'est pas nécessairement une voie facile à emprunter, mais n'est-ce pas l'une des rares qui nous permette, un tant soit peu, de nous libérer de la multiplicité des contraintes que nous impose notre environnement "naturel" ? "C'est moins d'avoir à pousser son rocher vers le sommet de la montagne qui pose problème à Sisyphe que de ne pas même avoir le choix de la face qu'il doit escalader avec son fardeau. Si l'on veut, avec Albert Camus, imaginer Sisyphe heureux, il faut que, d'une façon ou d'une autre, il puisse conquérir ce choix ${ }^{(4)}$."

Accepter de faire face aux difficultés - si intenses soient-elles - liées à la volonté de se rapprocher de l'autre est sans doute une manière privilégiée de parvenir à cette conquête d'une parcelle de liberté, à cet élément de libération. Il ne s'agit évidemment pas, en l'occurrence, de suggérer notamment que chacun de nous devienne obligatoirement polyglotte! Il suffit, beaucoup plus simplement, que nous nous réjouissions de l'existence même de la diversité linguistique, tout en faisant, le cas échéant, l'effort d'accéder, ne serait-ce que très partiellement, à un petit nombre d'autres langues, disons au moins une ! 


\section{Le fait diasporique généralisé}

Nous sommes de plus en plus nombreux à ne pas vivre sur les terres réelles ou mythiques de nos ancêtres. Ce fait concerne au premier chef les diasporas constituées (de plus ou moins longue date), telles les diasporas arménienne, chinoise, juive, etc. Mais il caractérise aussi la multiplicité des devenirs individuels ou collectifs liés aux phénomènes migratoires massifs des temps modernes, et cela même si ceux-ci n'aboutissent pas à l'institution de diasporas identifiées comme telles ${ }^{(5)}$.

De tels brassages ne peuvent qu'avoir d'importantes conséquences sur la perception individuelle et collective des questions identitaires. Cela vaut pour les populations migrantes elles-mêmes et donc pour les "minorités nationales" que nolens volens elles constituent au moins temporairement lors de leur arrivée sur de nouvelles terres. Mais cela vaut aussi pour les populations d'accueil, pour des "majorités" troublées dans leur quiétude par des phénomènes démographiques qu'elles maîtrisent mal, et dès lors tentées par des réactions de repli sur une "identité nationale" dont ce qui s'est passé à ce sujet dans notre pays au cours des derniers mois montre bien la vanité mais aussi le caractère particulièrement inquiétant.

Si la lutte contre les inégalités sociales et leur permanente aggravation, tant à l'échelle nationale qu'à celle du monde, constitue une évidente priorité, l'organisation du "vivre ensemble" - qui est la finalité de tout pacte social - n'en passe pas moins par l'assomption et le dépassement des difficultés inhérentes à la coexistence d'histoires, de mémoires, de cultures différentes sur un même territoire. Personne ne peut prétendre détenir la solution de cette épineuse difficulté. Il n'en est que plus utile d'ouvrir un débat dans cette perspective.

\section{Ni souverainisme ni communautarisme: la République !}

Existe-t-il une voie intermédiaire entre le souverainisme et le communautarisme? La réponse à cette question ne peut résulter que d'un retour aux principes constitutifs de la nation : l'article premier de la Constitution et la devise républicaine. Mais il existe à cela un préalable : la nécessité absolue de respecter la distinction essentielle évoquée plus haut entre communautés et cultures. Quel que soit le rôle des collectivités humaines spécifiques dans la genèse et la préservation des faits de culture, ceux-ci doivent impérativement être mis en partage au sein de la société, reconnus comme biens publics et donc placés sous responsabilité collective. On ne peut que regretter, de ce point de vue, que l'inscription en 2008 des langues régionales dans la Consti- 
tution française les ait "affectées" aux Régions au lieu d'en faire des biens communs à toute la société, ce qui, soit dit au passage, aurait aussi permis de ne pas "oublier" de façon consternante les autres langues d'héritage, celles qu'on qualifie (un peu curieusement) de "minoritaires" dans la Charte européenne (le yiddish, le ladino, le berbère, le romani, et tant d'autres...).

Si l'on accepte le préalable de la distinction ci-dessus recommandée, la relecture de la Loi fondamentale ne manque pas d'ouvrir des pistes particulièrement précieuses pour aller de l'avant. L'affirmation de la laïcité de la République d'abord, qui ne saurait se réduire à la seule (et indispensable) séparation des Églises et de l'État mais qui devrait

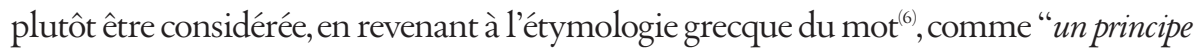
de reconnaissance réciproque de l'égale dignité des cultures "(7)". Et par là même de l'égale dignité des langues, qu'on ne saurait dès lors hiérarchiser en termes de "valeur" (une affirmation qui ne remet pas en question, est-il besoin de le souligner, la nécessité de reconnaître au français son irremplaçable rôle national). Les trois finalités affirmées par la devise nationale ensuite. La liberté, ce bien précieux entre tous, illustré en l'occurrence par celle d'avoir accès sans contrainte à d'autres façons de nous exprimer. L'égalité, qui, selon la Déclaration des droits de l'Homme, est bien une égalité en droits - incluant celui de contribuer pour chacun à faire vivre la ou les langues de son choix. La fraternité enfin, cette autre expression de la nécessaire reconnaissance de l'autre comme proche.

Indivisibilité, laïcité, liberté, égalité, fraternité, quels beaux mots pour porter l'avenir de nos langues ! Et en particulier pour dire aux générations les plus récemment "issues de l'immigration" que leur nécessaire adhésion à la francité et à l'usage de la langue française n'est en rien contradictoire avec la responsabilité (qu'ils partagent avec leurs compatriotes plus anciennement implantés dans le territoire national) de préserver et d'entretenir la multiplicité des langues auxquelles l'histoire de notre pays nous a si heureusement donné accès. Cette prise de conscience ne saurait toutefois être seulement la leur : elle ne peut avoir de réelle portée que si elle est partagée par tous les citoyens, quel que soit leur passé.

\section{Notes}

1. Paris, Le Seuil, 2004.

2. Lazar Philippe, Court Traité de l'âme, Paris, Fayard, 2008.

3. Cité par Vieira Domingos Lourenço dans la revue Diasporiques, $\mathrm{n}^{\circ}$ 9, mars 2010, p. 46.

4. Lazar Philippe, op. cit., p. 117.

5. Une revue telle que Diasporiques/Cultures en mouvement trouve sa raison d'être dans la prise en compte de ce fait majeur - sans doute l'une des retombées les plus importantes de la mondialisation.

6. "Laios", l'une des expressions du concept de "peuple", considéré en l'occurrence dans la multiplicité de ses composantes.

7. Lazar Philippe, Autrement dit laïque, Paris, Liana Levi, 2003, p. 92. 